\title{
Tarsal-carpal coalition syndrome
}

INSERM

\section{Source}

INSERM. (1999). Orphanet: an online rare disease and orphan drug data base. Tarsalcarpal coalition syndrome. ORPHA:1412

Tarsal-carpal coalition syndrome is characterised by fusion of the carpals, tarsals, and phalanges. 